\title{
AN ANALYSIS OF NORM PROCESSES IN TAX COMPLIANCE
}

\author{
Michael Wenzel
}

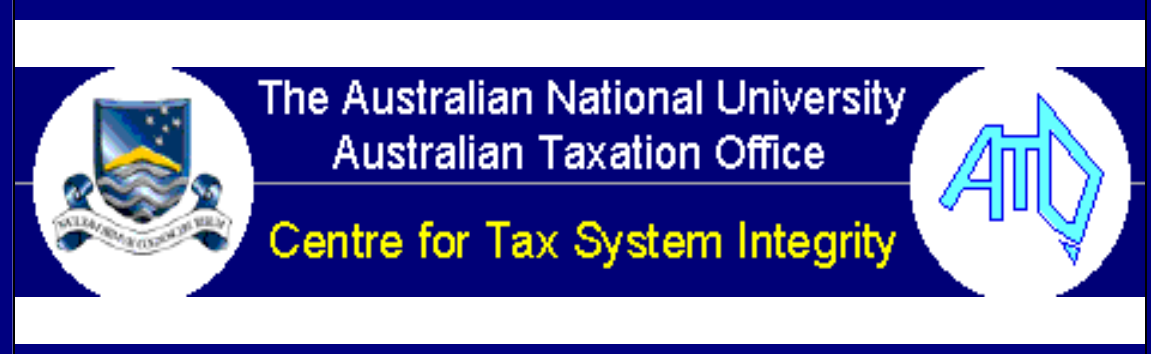

WORKING PAPER No 33

July 2002 


\title{
AN ANALYSIS OF NORM PROCESSES IN TAX COMPLIANCE
}

\author{
Michael Wenzel
}

SERIES' EDITOR

Karen Byng

\author{
Centre for Tax System Integrity \\ Research School of Social Sciences \\ Australian National University \\ Canberra, ACT, 0200
}

ISBN 0642768323

ISSN 1444-8211

\section{WORKING PAPER No 33}

July 2002 
(C) Centre for Tax System Integrity, Research School of Social Sciences, Australian National University 2002

(C) Commonwealth of Australia 2002

National Library of Australia

Cataloguing-in-Publication data:

Wenzel, Michael, 1966- .

An analysis of norm processes in tax compliance.

Bibliography.

ISBN 0642768323.

1. Taxpayer compliance - Australia. 2. Taxation Australia - Public opinion. I. Centre for Tax System Integrity. II. Title. (Series : Working paper (Centre for Tax System Integrity); no. 33).

336.2910994

If you would like to make any comments on this working paper please contact the author directly within 90 days of publication.

\section{Disclaimer}

This article has been written as part of a series of publications issued from the Centre for Tax System Integrity. The views contained in this article are representative of the author only. The publishing of this article does not constitute an endorsement of or any other expression of opinion by the Australian National University or the Commissioner of Taxation of the author's opinion. The Australian National University and the Commissioner of Taxation do not accept any loss, damage or injury howsoever arising that may result from this article. This article does not constitute a public or private ruling within the meaning of the Taxation Administration Act 1953, nor is it an advance opinion of the Commissioner of Taxation. 


\section{THE CENTRE FOR TAX SYSTEM INTEGRITY WORKING PAPERS}

The Centre for Tax System Integrity (CTSI) is a specialised research unit set up as a partnership between the Australian National University (ANU) and the Australian Taxation Office (Tax Office) to extend our understanding of how and why cooperation and contestation occur within the tax system.

This series of working papers is designed to bring the research of the Centre for Tax System Integrity to as wide an audience as possible and to promote discussion among researchers, academics and practitioners both nationally and internationally on taxation compliance.

The working papers are selected with three criteria in mind: (1) to share knowledge, experience and preliminary findings from research projects; (2) to provide an outlet for policy focused research and discussion papers; and (3) to give ready access to previews of papers destined for publication in academic journals, edited collections, or research monographs.

Series' Editor:

Karen Byng 


\begin{abstract}
It is often argued that individual ethics and social norms affect tax compliance. However, for this insight to benefit tax administration, we need to understand better how and when ethics and norms affect taxpaying decisions. This study used survey data to investigate in more detail effects on levels of compliance of personal ethics and social norms. The results suggest that individual ethics are indeed strongly related to tax compliance. Social norms, that is ethical views attributed to a social group, affect tax compliance only when people identify with that group and, as a consequence, internalise the norms as part of their own ethical beliefs. The findings have interesting implications for compliance management strategies that deliberately or incidentally affect social norms.
\end{abstract}

The study used data from The Community Hopes, Fears, and Actions Survey (Braithwaite, 2001), involving 2040 Australians. Self-reported tax compliance (aggregated across a number of taxpaying behaviours) was greater when one's personal norms prescribed compliance. In contrast, the effects of perceived social norms, that is ethical beliefs ascribed to most people, depended on participants' levels of identification with Australians. Only when respondents identified strongly as Australians was their selfreported compliance positively related to the perceived social norm. When personal ethics were statistically controlled, this effect disappeared, indicating that identification led to the internalisation of social norms: being internalised, social norms are part of one's ethical make-up and thus affect one's behaviour.

The findings suggest that regulatory strategies to increase tax compliance could refer to ethical beliefs, for instance through persuasive appeals that attempt to increase taxpaying ethics. However, it would be difficult to change each taxpayer's ethics individually. Because personal beliefs are (at least partly) based on social norms of groups with whom taxpayers identify, it would therefore be a better strategy to refer to broader social norms. Persuasive appeals as a means to increase tax compliance should refer to favourable social norms in the public and utilise their 'appeal' to taxpayers. However, their 'appeal' and internalisation as personal beliefs depend on a sufficient level of identification with the group to which the norms are attributed (for example, Australians, occupational groups). That is, appeals that refer to ethical taxpaying norms of a certain group need to ensure that taxpayers identify with that group sufficiently. Normative appeals could be combined with measures that try to increase levels of identification. 


\title{
An analysis of norm processes in tax compliance
}

\author{
Michael Wenzel
}

In the early days of empirical tax compliance research, the works of Schmölders (1970), Vogel (1974), Spicer and Lundstedt (1976) and others challenged the confines of economic self-interest models in the tradition of Allingham and Sandmo (1972) and stressed that non-economic social factors such as social norms and individual morality could have a significant impact on taxpaying behaviour. Since then, consistent evidence has accumulated for the impact on tax compliance of privately held ethical and moral convictions, which are referred to here as personal norms (see Schwartz, 1977). While the relevance of social norms (see Cialdini \& Trost, 1998), that is the behaviours and shared ethical beliefs attributed to others, has also been demonstrated, the empirical evidence is generally more ambiguous. In the present paper, I will argue that a more sophisticated theoretical analysis of norm processes is required to understand and acknowledge the substantial role that social norms can play in taxpaying behaviour. The analysis presented here emphasises the role of social identification as a process transforming a social group into a self-category and reference group whose norms are internalised and acted upon as one’s own personal views (Turner, 1987b, 1991).

\section{Personal and Social Norms of Tax Compliance}

Various studies have demonstrated the role of personal norms for taxpaying behaviour. Schwartz and Orleans (1967) provided early experimental evidence that appeals to taxpayers' personal conscience could increase their tax compliance. Although the conceptual replication of this study by McGraw and Scholz (1991) did not show an equivalent effect on actual tax return data, the moral appeal had consistent effects on more 'peripheral' taxpaying attitudes and behaviours. Further experimental evidence comes from a simulation study by Bosco and Mittone (1997). Personal moral concerns were operationalised as the existence of a redistributive purpose of the tax collection, where tax evasion would be at the cost of less affluent others; the factor accounted significantly for the observed degree of evasion. There are also a number of survey studies showing that general honesty (Porcano, 1988); ethical convictions concerning taxpaying (Reckers, 
Sanders \& Roark, 1994), or the anticipation of experienced guilt over non-compliance (Grasmick \& Bursik, 1990; Scott \& Grasmick, 1981) were significantly related to tax compliance.

However, studies on effects of personal taxpaying norms, ethics and morality rarely ask for the origin of these personal norms. Personal tax norms are certainly to a large part based on processes of social learning and absorption from the environment and thus have a social basis (Weigel, Hessing \& Elffers, 1987; see Schwartz, 1977). Moreover, personal norms need not be understood as stable and enduring personality characteristics, but, because they are largely of a social nature, rather as depending on and varying with the groups and social norms one refers to at any given point in time (Abrams \& Hogg, 1990; Terry, Hogg \& White, 2000; Turner, 1987b, 1991). In this sense, studies that test and thus control for the effects of personal norms may underestimate the role of social norms for tax compliance. For instance, Grasmick and Bursik (1990) tested in their interview study for effects of personal norms and social pressure, operationalised as experience of guilt and loss of respect in the eyes of valued others, respectively. Regression analyses showed that personal norms were significantly related to anticipated tax cheating, while social norms were not (even though their zero-order correlation with tax cheating was significant).

However, there is also evidence showing that social norms do impact on taxpaying behaviour. In an experimental study by Alm, McClelland \& Schulze (1999), participants who learned that the majority rejected a more severe enforcement showed subsequently lower levels of compliance. In a field-experiment, Wenzel (2001a, 2001b) provided a group of taxpayers with feedback about survey findings showing that people underestimate other taxpayers' normative beliefs supporting tax compliance. Compared to control groups, the feedback was partly effective in significantly reducing deduction claims. Moreover, a number of studies found that people with more non-compliant attitudes or behaviours perceived tax non-compliance to be more prevalent among people known to them (for example, De Juan, Lasheras \& Mayo, 1994; Porcano, 1988; Spicer \& Lundstedt, 1976; 
Wallschutzky, 1984; Webley, Cole \& Eidjar, 2001). However, the direction of causality underlying this finding is ambiguous (Wenzel, 2001a, 2001b). Furthermore, the findings seem more consistent for taxpayers' perceptions of tax compliance among friends and people known to them, but there have been negative findings for the perceived prevalence of tax non-compliance among taxpayers in general (Brooks \& Doob, 1990; Hasseldine, Kaplan \& Fuller, 1994). This would suggest that social norms are not a promising channel for regulation attempts, because campaigns could hardly address the norms of each taxpayer's more immediate peer groups, while broader societal norms could be targeted but seem less relevant to people (see Bardach, 1989).

One reason for the inconsistent findings could be that social norms do not exist in an unstructured social field. Rather, others' beliefs and behaviours become normative when we refer to these others as a relevant reference group (for example, Kelley, 1952). Conversely, if our research refers to an irrelevant group of taxpayers, and the beliefs and behaviours prevalent in that group, we would be unlikely to observe positive effects of these alleged norms. Hence, the discussion so far suggests that a better appreciation of the role of social norms requires an understanding of how people structure their social field whereby they consider some social norms as relevant to themselves while they reject other social norms. Further, we need to recognise the significance of social norms even where they become an invisible part of our personal ethical views. We need to overcome the simple polarity between personal and social norms of tax compliance, and instead address the process whereby external social norms become part of a person's own norms and values.

\section{A Self-Categorisation Perspective on Social Norms}

Tax compliance research requires greater theoretical refinement with regard to the role of social norms. Otherwise we are at risk of overlooking their substantial impact. As a kind of dramatic device, let me take an unusual step and anticipate a finding of the present study. The correlation between the perceived social norm of tax compliance and respondents' self-reported tax compliance was found to be $\underline{r}=0.00, \underline{p}=0.995, \underline{N}=1445$. That is, there was no sign of a relationship between social norms and tax compliance, and we could 
conclude that social norms do not have any impact whatsoever. In fact, however, such a conclusion would be premature and theoretically naive.

Self-categorisation theory (SCT) (Turner et al., 1987) offers a more refined analysis of processes of social norms and social influence (in the area of tax compliance, see Sigala, 1999; Sigala, Burgoyne \& Webley, 1999). The analysis differs from traditional dualprocess accounts of social influence that distinguish between informational influence involving true attitude change due to the informational value of the message, and normative influence involving mere outward compliance without being reflected in a change of one's personal beliefs (Deutsch \& Gerard, 1955). While these traditional approaches regard norms as external pressure to which the person succumbs against inner convictions, SCT argues for a unified social influence process where normative and informational influence are interactive processes (Turner, 1987b). Importantly, normative influence is true influence based on the internalisation of the views of others with whom we expect to agree in the given context. This expectation to agree is based on one's perceived interchangeability with these others based on processes of self-categorisation. As members of the same social category we are similar and expect to hold similar views. Where this expectation is violated and there is disagreement, a state of uncertainty results that can be reduced by bringing one's own view in line with the views of the samecategory others (McGarty et al., 1993; Turner, 1987b). The essential conclusions for the present research are that, first, people are more likely to be influenced by others who are considered members of one's relevant self-category; that is, members of the group with which one identifies in a given situation. Second, such influence means that the views and behavioural tendencies of fellow group members are internalised as one's true personal convictions (Abrams \& Hogg, 1990; see also Kelman, 1958).

In contrast, when the influence source (that is, those others whose taxpaying beliefs and behaviours we are faced with) is not considered part of one's self-category or group with which one identifies, there is no expectation to agree because 'they are different'. In fact, 
people might even distance themselves from those others because, by accentuating the differences, people achieve or maintain a distinctive and positive social identity (Turner, 1987a; see Tajfel \& Turner, 1986). Hence, social norms attributed to other social categories and groups with which one does not identify in the given context may have a counterproductive effect and lead to a form of reactance (see Brehm \& Brehm, 1981). However, we would expect such a rejection only where the social norm, attributed to an outgroup, does not coincide with the perceiver's personal or internalised norm; thus when positions on this norm fit the differentiation from the outgroup and can be accentuated to define one's social identity.

\section{Hypotheses}

From these considerations, we can derive the following hypotheses. First, because social norms are effective through their internalisation as personal norms, but social norms are ineffective or even counterproductive where internalisation does not occur, it is predicted that:

(H1) Overall, personal taxpaying norms will be positively related to tax compliance, while social taxpaying norms will not.

Second, social norms would only have a positive effect when attributed to one's ingroup, that is, the group with which one identifies. When identification with the group to which the social norm is attributed is weak, there should be no effect. We do not expect a negative effect, because the social norm could coincide with one's personal or internalised conviction and would thus not be rejected:

(H2) The impact of social norms will be moderated by level of identification:

(a) social norms will have a positive impact for the strongly identified; but

(b) no effect for the weakly identified.

Third, because, for the strongly identified, social norms have true influence through their internalisation as personal norms, social norms will not have any impact beyond the effect 
of personal norms. In contrast, for weakly identified respondents, social norms should even have a negative effect on tax compliance, once the possibility of coinciding personal norms is controlled. That is, for weakly identified respondents, controlling for personal norms renders the social norm truly external; it is not held by a relevant reference group and it differs from the personal norm:

(H3) When controlling for the effect of personal norms:

(a) for the strongly identified, social norms will no longer have a significant positive effect; and

(b) for the weakly identified, social norms will have a negative effect on tax compliance.

Importantly, for those strongly identified with the respective group, a reduction of the positive effect of social norms when personal norms are controlled would be evidence for the mediation of the normative influence through a process of internalisation. As a matter of clarification, the present study will deal with injunctive social and personal norms that reflect what people think one should do; these need to be differentiated from descriptive norms that reflect what people generally actually do (Cialdini, Kallgren \& Reno, 1991).

\section{Method}

\section{Participants}

The data were taken from The Community, Hopes, Fears, and Actions Survey (Braithwaite, 2001). The self-completion questionnaire was sent to a sample of 7754 Australian citizens drawn from the Australian electoral roll. Subtracting cases where the mail was returned to sender, addressees were deceased, etc., 7003 questionnaires were effectively sent out (for procedural details, see Mearns \& Braithwaite, 2001). After repeated appeals for participation, 2040 respondents, or $29 \%$, returned their questionnaires. The response rate 
for this rather long questionnaire compares with experiences from other mail surveys on tax issues in Australia (Wallschutzky, 1984, 1996). Compared to census data, the sample proved broadly representative for the Australian population, but it tended to underrepresent people younger than 35 and overrepresent people between 40 and 65 years of age, as well as those with higher education (Mearns \& Braithwaite, 2001).

However, the number of valid cases for the present analyses was further reduced by a relatively large number of missing values (listwise $\underline{N}=1306$ ). Inspection of differences between the cases included versus those excluded due to missing values, however, suggests a meaningful reduction of valid cases. Measures of tax compliance behaviour require that respondents actually fill in tax returns, while the total sample of respondents was taken from the electoral roll, of whom some might have no obligation to lodge tax returns. Other respondents might leave it to their partners to fill in their tax returns for them. Correspondingly, a large number of people aged 65 or older and respondents with very low personal or family income had missing values. Likewise, a higher proportion of female respondents had missing values. Indeed, the dropping out of missing cases seemed to render the valid sample more typical for respondents who actually make taxpaying decisions. However, some of the survey questions addressed sensitive issues (for example, illegal behaviour) that may have caused certain respondents to deny an answer. The participants in the final sample were between 18 and 89 years old $(\underline{\mathrm{Mdn}}=45) ; 50.5 \%$ were male, $49.5 \%$ were female.

\section{Procedure}

The questionnaire was sent to respondents with a reply-paid envelope and an accompanying letter. The letter explained the intent of the study, the researchers' relationship to the Australian Taxation Office, and guaranteed strict confidentiality of responses. An identification number on the questionnaire allowed a targeted follow-up (with reminder letters and new questionnaires) for cases where the questionnaire was not returned by a certain deadline. Excluding breaks, which were explicitly recommended at 
various stages of the questionnaire, respondents would have needed an estimated 1.5 hours to fill it in.

\section{Questionnaire}

\section{$\underline{\text { Tax Compliance }}$}

A number of items with different response formats were used to measure five forms of tax non-compliance. For each form of non-compliance, scores were transformed into

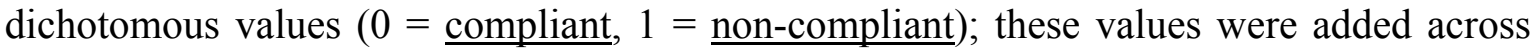
the different forms to receive a total score of non-compliance (from 0 to 5). The final measure thus captured a respondent's self-reported number of non-compliant taxpaying behaviours $(\underline{\mathrm{M}}=0.43 ; \underline{\mathrm{SD}}=0.76)$. These behaviours were measured as follows:

Non-lodgment. Two questions were combined for self-reported non-lodgment: 'Should

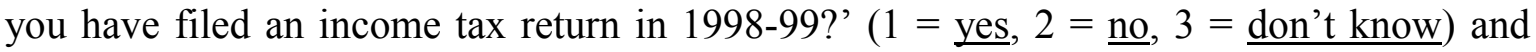
'Did you file an income tax return for 1998-99?' $(1=$ yes, $2=\underline{\text { no }}, 3=\underline{\text { not yet }})$. If respondents reported an obligation to lodge a tax return or were unsure about it ( 1 or 3 for the first question) and did not lodge, or have not yet lodged, a tax return ( 2 or 3 for the second question), they were defined as non-lodgers or late lodgers and received a score of 1 (non-compliant). Otherwise they received a score of 0 (compliant). Sixteen respondents (1.2\%) admitted non-lodgment.

Tax debt. A single question was used as a measure of non-compliance in terms of not paying one's tax debts: 'Do you have an outstanding debt with the Tax Office?' ( $1=$ yes, 2 $=\underline{\text { no }}$, recoded into 1 and 0 , respectively). Fifty respondents (3.8\%) reported having a tax debt.

Pay income. Four items measured whether or not respondents declared all their pay income. If respondents had a score of 0 for all of the following questions, they were defined as fully compliant (0); otherwise they were defined as not fully compliant or noncompliant. (1): 'As far as you know, did you report all the money you earned in your 199899 income tax return?' $(0$ = yes, $1=\underline{\text { no }})$; 'Have you worked for cash-in-hand payments in 
the last 12 months? By cash-in-hand we mean cash money that tax is not paid on.' $(1=$ yes, $2=\underline{\text { no}}$, recoded into 1 and 0 , respectively); 'People earn income from many different sources, [...] Think about each of the sources of income listed below, and select the response that best describes your 1998-99 income tax return.' $(1=\underline{\text { received none, }} 2=\underline{\text { did }}$

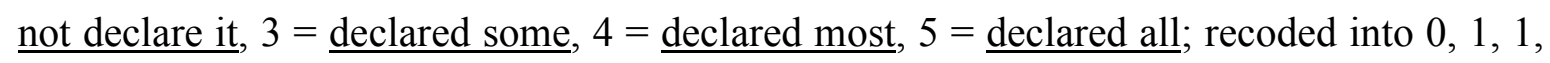
1, and 0, respectively): (1) Salary, wages; (2) Honorariums, allowances, tips, bonuses, director's fees. One-hundred and fifty-six respondents $(11.9 \%)$ indicated not having reported all their pay income.

Non-pay income. The previous question was continued for non-pay income (see Wenzel, 2002): (3) Eligible termination payments; (4) Australian government allowances like Youth Allowance, Austudy, Newstart; (5) Australian government pensions, superannuation pensions, and other pensions and annuities; (6) Interest; (7) Dividends. If respondents had a score of 0 for all the above questions, they were defined as fully reporting their non-pay income and thus as being compliant (0); otherwise they were defined as not fully compliant or non-compliant (1). Eighty-seven respondents (6.7\%) reported they had not declared all their non-pay income.

Deductions. Two questions addressed respondents' deduction claims: 'As far as you know, did you exaggerate the amount of deductions or rebates in your 1998-99 income tax return?' $(1=\underline{\text { a lot }}, 2=$ quite a bit, $3=\underline{\text { somewhat }}, 4=\underline{\text { a little, }}, 5=\underline{\text { not at all; }}$ recoded into 1 , $1,1,1$, and 0 , respectively); 'Think of the deductions and rebates you claimed in your 1998-99 income tax return. Would you say you were ...' $(1=\underline{\text { absolutely confident that }}$ they were all legitimate, $2=$ a bit unsure about some of them, $3=$ pretty unsure about quite a lot, 4 = haven't a clue, someone else did it; recoded into $0,1,1$, and 1 , respectively). If respondents had a score of 0 for both questions, they were defined as fully compliant $(0)$; otherwise they were coded as not fully compliant or non-compliant (1). Two-hundred and fifty-six respondents (19.6\%) reported exaggerated deduction claims. 


\section{$\underline{\text { Identification }}$}

Inclusive identification. Two items measured identification with Australians (see Haslam, 2001), which should approximate the group to which the perceived social norms (see below) might be attributed: 'Being a member of the Australian community is important to me', and 'I feel a sense of pride in being a member of the Australian community' $(1=\underline{\text { do }}$

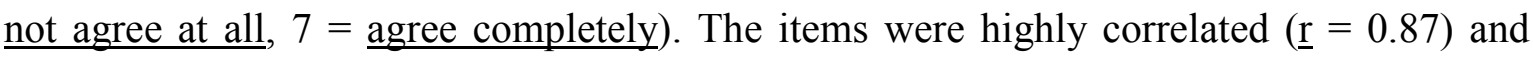
scores were averaged to obtain a measure of inclusive identification. However, the measure was highly skewed and truncated at the pole of high identification; $64 \%$ of respondents had a score of $6,6.5$, or $7(\underline{\mathrm{Mdn}}=6, \underline{\mathrm{M}}=5.82)$. A large portion of the variance in inclusive identification would thus be located at the high identification end of the scale, which would be inappropriate for tests of predictions about the impact of a high versus low degree of inclusive identification. Therefore, the measure was dichotomised, with scores lower than or equal to the midpoint of the scale (4) defined as low identification $(\underline{\mathrm{n}}=161)$ and scores greater than the midpoint of the scale defined as high identification $(\underline{\mathrm{n}}=1145){ }^{1}$

\section{$\underline{\text { Norms }}$}

Social norm. The social norm referred to the perceived injunctive norms of 'most people' and were measured by three items $(1=\underline{\text { no!! }, 5}=$ yes!! $)$ : 'Do MOST PEOPLE think they should honestly declare cash earnings on their tax return?'; 'Do MOST PEOPLE think it is acceptable to overstate tax deductions on their tax return?' (reverse-coded); and 'Do MOST PEOPLE think working for cash-in-hand payments without paying tax is a trivial offence?' (reverse-coded). The items showed a rather low, but sufficient, internal consistency $(\alpha=0.60)$ and scores were averaged to obtain a measure of the social norm.

Personal norm. The personal norm referred to one's own injunctive norms concerning taxpaying and were measured by the equivalent three items ( $1=\underline{\text { no!! }} 5$ = yes!! $)$ : 'Do YOU

\footnotetext{
${ }^{1}$ Dichotomisation of variables is often criticised for loss of information. The reason for using the procedure in the present context may be conceived as focussing on the relevant information, given the empirical peculiarities of the variable. It is less relevant whether respondents indicated scale points 6 or 7 for their degree of identification (rather, this may reflect some personal preference for extreme or less extreme responses); more meaningful and important is whether respondents tended towards the one or the other end of the identification scale. However, variance in this respect would be diluted by the variance of a large number of cases at the upper end of the scale, if the original scale were used.
} 
think you should honestly declare cash earnings on your tax return?'; 'Do YOU think it is acceptable to overstate tax deductions on your tax return?' (reverse-coded); and 'Do YOU think working for cash-in-hand payments without paying tax is a trivial offence?' (reversecoded). The items showed a rather low, but sufficient, internal consistency $(\alpha=0.58)$ and scores were averaged to obtain a measure of the personal norm.

A factor analysis with Varimax rotation for the six norm items confirmed the conceptual distinction between personal and social norms. It yielded a two-factor solution (Eigenvalues of 1.86 and 1.46, respectively) that explained 55\% of the variance. All social norm items loaded on one factor, and all personal norm items loaded on the other factor (with factor loadings greater than 0.65 and no substantial cross-loadings).

\section{$\underline{\text { Background Variables }}$}

Respondents were asked to indicate their age, $\underline{\text { sex }}(1=\underline{\text { male }}, 2=\underline{\text { female }})$, personal income, and family income (each on a scale from none, $\underline{5}, \underline{10}, \underline{15}$, etc. to $\underline{75}, \underline{100}, \underline{250+\text { thousand }}$ dollars).

\section{Results}

Hierarchical regression analyses were used to test the predictions. In all these regressions, the first step controlled for background variables of sex, age, personal income and family income. Results for these variables will not be discussed in the present paper, as this has been done in earlier research based on the same data set (Wenzel, 2002). To test Hypothesis 1, first, the effect of Social Norm on tax compliance was tested after controlling for background variables. As predicted, there was no significant effect ( $\beta=$ $-0.02, \underline{\mathrm{ns}})$. In a second analysis, the effect of Personal Norm was tested after controlling for background variables. As predicted, Personal Norm had a significant effect $(\beta=-0.26, \underline{p}<$ 0.001); respondents who expressed a strong personal norm of tax honesty and morality reported being more compliant. The same findings were obtained when Social and Personal Norms were included simultaneously as predictors to test for their unique effects. Their common inclusion after controlling for background variables contributed 
significantly to the variance explained, $\underline{\mathrm{F}}(2,1299)=45.93, \underline{\mathrm{p}}<0.001, \underline{\mathrm{R}^{2} \text { Change }}=0.06$, $\underline{\mathrm{R}^{2}}=0.11$. However, only the Personal Norm had a significant effect $(\beta=-0.26, \underline{p}<0.001)$, whereas there was no effect for Social Norm $(\beta=0.01$, $\underline{\text { ns }})$.

Table 1: Hierarchical regression of tax non-compliance on background variables, social norm and identification, their interaction, and personal norm

\begin{tabular}{|c|c|c|c|c|}
\hline Predictor & Step $1(\beta)$ & Step $2(\beta)$ & Step $3(\beta)$ & Step $4(\beta)$ \\
\hline Age & $-0.19^{* * *}$ & $-0.18^{* * * *}$ & $-0.18^{* * *}$ & $-0.11^{* * *}$ \\
\hline Sex & $-0.13^{* * *}$ & $-0.13^{* * *}$ & $-0.13^{* * *}$ & $-0.13^{* * *}$ \\
\hline Personal Income & $-0.10^{* *}$ & $-0.11^{* *}$ & $-0.11^{* *}$ & $-0.10^{* *}$ \\
\hline Family Income & 0.01 & 0.02 & 0.02 & 0.04 \\
\hline Identification & & $-0.08^{* *}$ & $-0.09^{* *}$ & $-0.08^{* *}$ \\
\hline Social Norm & & -0.01 & -0.01 & 0.02 \\
\hline Ident. XSocial N. & & & $-0.07^{* *}$ & $-0.08^{* *}$ \\
\hline Personal Norm & & & & $-0.26^{* * *}$ \\
\hline (Constant) & -0.04 & -0.04 & -0.03 & -0.01 \\
\hline$\underline{\mathrm{R}^{2}}$ & 0.042 & 0.048 & 0.053 & 0.114 \\
\hline$\underline{\mathrm{R}^{2} \text { change }}$ & 0.042 & 0.006 & 0.005 & 0.062 \\
\hline Fchange & $14.14^{* * *}$ & $4.23^{* *}$ & $6.69^{* *}$ & $90.48^{* * *}$ \\
\hline$\underline{\mathrm{df}}$ & 4,1301 & 2,1299 & 1,1298 & 1,1297 \\
\hline
\end{tabular}

Note. ${ }^{*} \mathrm{p}<0.05, \stackrel{*}{* *}<<0.01, \stackrel{* * *}{\mathrm{p}}<0.001$

For Hypothesis 2, the interaction effect of Social Norm and Identification was investigated. After controlling for background variables in the first step, and for main effects of Social Norm and Identification in the second step, the interaction of both variables was entered in the third step. Following Aiken and West (1991), all variables were first centred (standardised) before the product term of Social Norm and Identification was built. Table 1 displays the results: As predicted, the interaction effect was statistically significant ( $\beta=$ 
$-0.07, \underline{p}=0.010)$. The interaction contributed significantly to the variance explained, $\underline{F}(1$, $1298)=6.69, \underline{p}=0.010, \underline{\mathrm{R}^{2} \text { Change }}=0.01$. There was also a main effect of Identification in the second step $(\beta=-0.08, \underline{p}=0.005)$, reflecting that respondents who identified more strongly as Australians reported being more compliant. To complement these analyses, controlling for Personal Norm in the fourth step of the regression $(\beta=-0.26, p<0.001)$ did not diminish the size or significance of the interaction effect $(\beta=-0.08, \underline{p}=0.004)$.

Simple slope analyses were applied to specify the meaning of the observed interaction effect (Aiken \& West, 1991). This technique provides us with regression effects of Social Norm for high and low levels of Identification $(+1$ versus -1 standard deviation), while controlling for background variables. For high levels of identification, the analysis yielded a significant negative effect of Social Norm on non-compliance $(\beta=-0.08, \underline{p}=0.026)$, as Hypothesis 2 predicted. Respondents who identified strongly with Australians reported being more compliant, when they perceived a strong social norm that one should be

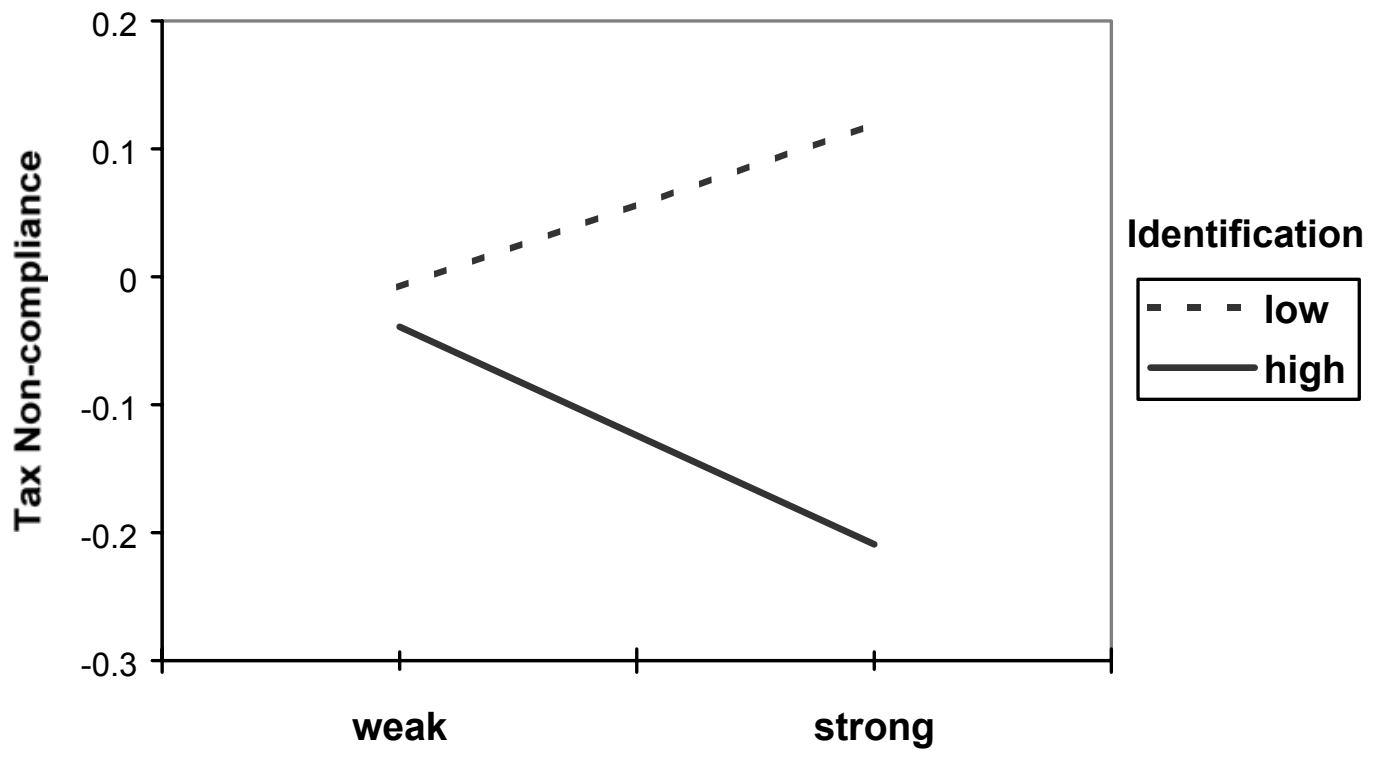

Social Norm

Figure 1. Simple slopes for high and low levels of identification: Effects of social norms on tax non-compliance. 
truthful in one's taxes. In contrast, for low levels of Identification, the effect of Social Norm $(\beta=0.06, \underline{\mathrm{ns}})$ was not significant. Again, as predicted, a perceived social norm against tax cheating was ineffective when respondents did not identify with the group holding this norm (see Figure 1).

Hypothesis 3 predicted that, for the strongly identified, the positive effect of social norms should disappear when their internalisation as personal norms was controlled. Hence, the previous simple slope analysis was extended and Personal Norms were entered in a fourth step. For respondents strongly identified as Australians, the effect of Social Norm was reduced and no longer significant $(\beta=-0.06, \underline{\mathrm{ns}})$. This finding is consistent with the assumption that the positive effect of social norms for the highly identified would be mediated by internalisation of the social norms (see Baron \& Kenny, 1986). However, as can be seen in Figure 2, the Social Norm still has a negative, even if non-significant, effect on non-compliance; the mediation was only partial.

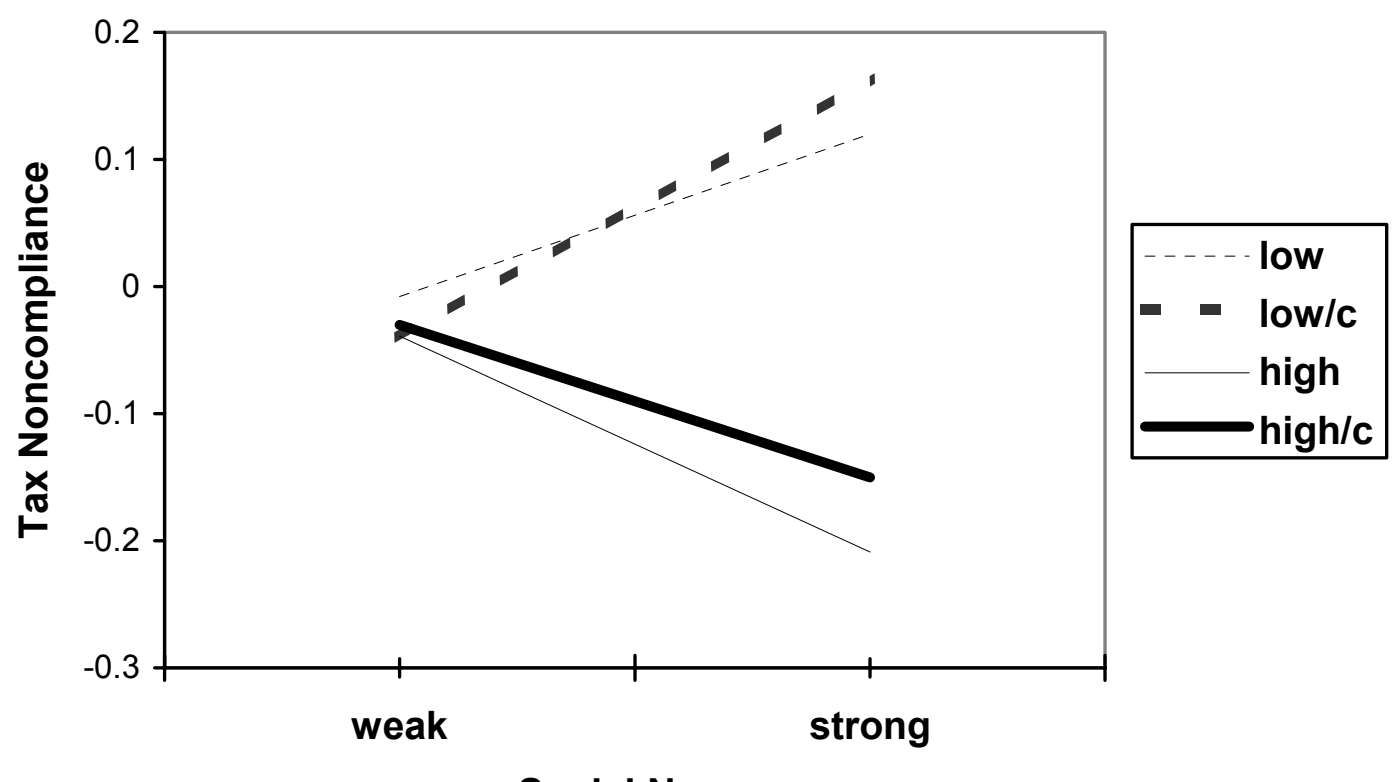

Social Norm

Figure 2. Simple slopes for high and low levels of identification: Effects of social norms on tax non-compliance, controlling for personal norms.

Note. The bold lines are the simple slopes controlling for personal norms; the non-bold lines represent the earlier analysis, not controlling for personal norms. 
For respondents whose identification was weak, Hypothesis 3 also predicted that social norms would have a negative effect on compliance, once a coincidental overlap with personal norms was controlled. Again, the earlier simple slope analysis was extended and Personal Norm was entered in a fourth step. For respondents who did not identify as Australians, the perceived Social Norm now had a significant counterproductive effect $(\beta=$ $0.10, \underline{p}=0.010)$. This was consistent with the assumption that, for the weakly identified, social norms can elicit reactance and cause taxpayers to distance themselves away from the social norm (see Figure 2). Comparing Figures 1 and 2, note that the inclusion of Personal Norm changed the simple slopes, but not the relation of the slopes to each other. Hence, as determined in the earlier analysis testing for the interaction, controlling for Personal Norm did not reduce the size or significance of the interaction effect.

\section{Discussion}

The present research investigated the potential role of social norms in the area of tax compliance in more detail. It was argued and demonstrated that a theoretically naive analysis might prematurely conclude that social norms are irrelevant and have no impact on taxpaying behaviour. The data showed that, in fact, social norms had no simple relationship to self-reported tax compliance. In contrast, consistent with many earlier studies (for example, Grasmick \& Bursik, 1990; Reckers et al., 1994; Schwartz \& Orleans, 1967), personal norms, in the sense of individually held ethical views about taxpaying, had a significant and substantial effect on self-reported tax compliance.

However, based on an understanding of social norms from the perspective of selfcategorisation theory (Turner et al., 1987; Turner, 1991), the results confirmed that social norms can influence the behaviours of those who identify strongly with the group of people to whom the norms are attributed. Identifying with a group, one refers to it as a relevant reference group in the given context. Categorising oneself in terms of a group, one expects to agree with its other members and is motivated to bring one's own behaviour in line with the prototypical behaviours, norms and values of this self-category (Turner, 1987b). Furthermore, such an alignment is not a matter of succumbing to external pressure. Rather, through a process of self-categorisation, the norms and values of one's group are attributed 
to oneself and internalised as authentic aspects of one's social self. Consistent with this analysis, the effect of social norms was reduced to statistical insignificance when personal norms were controlled in the present study. Hence, the effect of social norms for those who identified strongly with the group were mediated by the internalisation of the social norms as personal norms.

In contrast, it was predicted and found that social norms would have no effect on tax compliance levels of those who did not identify with the group. Further, when a coincidental overlap between personal and social norms was controlled, so that tax ethics could be a dimension on which one might seek distinctiveness from 'those different others' with 'their different views' (see Turner, 1987a), social norms even had a significant negative effect on tax compliance. Instead of internalising the social norm and conforming to it, the norm was rejected, together with the rejection of, and disidentification from, the group holding this norm.

The present findings thus confirm the theoretical analysis and suggest that social norms can indeed influence people's taxpaying behaviour. The results are consistent with research by Terry and Hogg (1996; Terry et al., 2000) that explains, based on self-categorisation theory, the role of social norms in relation to Fishbein and Ajzen's (1975) theory of reason action (and Ajzen's, 1991, extended theory of planned behaviour). Given that Fishbein and Ajzen's (1975) model has also been influential in the area of tax compliance (for example, Lewis, 1982), it might be interesting to revisit this approach from the perspective suggested by Terry and colleagues, further encouraged by the present research.

However, this research has also some limitations. First, the statistical effects were not very strong. The final model did not account for much more than $11 \%$ of variance in tax compliance. Problems in measuring compliance could account in part for the weak effects. Respondents' concerns about social desirability and their fear that tax authorities could find out about their non-compliance might reduce the reliability and validity of the measure, thus reducing statistical relationships with predictor variables. However, social norm effects were also relatively small, namely smaller than the effects of the background variables sex, age and personal income. Again, measurement of constructs such as 
perceived social norms is burdened with much greater problems of reliability and validity than is the case for objective variables such as sex, age and income. Hence, for the complex construct of social norms the observed statistical relationships may underestimate true relationships.

Second, although controlling for personal norms rendered the significant social norm effect for the strongly identified respondents insignificant, and the insignificant social norm effect for the weakly identified respondents significant, the changes were only of small size. Specifically, the results indicated a mediation effect for the strongly identified, according to the three mediation criteria set out by Baron and Kenny (1986). First, the simple slope indicated a significant total effect of Social Norm on tax compliance; second, the mediator variable Personal Norm was significantly related to tax compliance; and third, the effect of Social Norm was no longer statistically significant when the mediator Personal Norm was controlled. However, in fact, the mediation was of small size and seemed only partial. The evidence for an internalisation process was rather weak.

There are good reasons for this though. While it was assumed that social norms would only be effective through their internalisation as personal norms, personal norms are not necessarily the same as the internalised norms of a particular group. Personal norms may be fed by norms of many different social groups with which one identifies, except if a certain group context is so salient in a given situation that it totally dominates one's current self-concept (see Simon, 1997). Personal norms may furthermore be based on one's individual identity, on intragroup comparisons and differentiation from other members of one's group, again except if the group is so salient that it is incompatible with intragroup differentiation (Turner, 1987a). If the ingroup (Australians) had been made salient and an Australian identity been activated when personal and social norms were measured, a stronger mediation effect should have resulted.

A third limitation is the correlational nature of the present data that does not allow any conclusions about causality. While the causal influence of social norms on behaviour is an obvious theoretical possibility, there are theoretical reasons to assume also a reverse process and thus a bidirectional relationship. People may misperceive social norms 
depending on their own beliefs and behaviour; and the misperceived norms may impact on their behaviour (Wenzel, 2001a, 2001b). While the present data does not allow any firm conclusions, a complex interaction effect was predicted and found, based on a detailed analysis of the causal impact of social norms on behaviour. It seems more difficult to interpret the interaction in terms of a reverse causal relationship. Yet, for more certainty about causal relationships, we would need to use experimental research designs.

A final limitation of the present research is the potentially limited validity of self-report measures (Elffers, Robben \& Hessing, 1992). Field-experiments using actual taxpayer data instead of self-reported compliance would be required to overcome this problem (Wenzel, 2001b).

While acknowledging these caveats, the present findings suggest that social norms can influence tax compliance. Social norms about ethical taxpaying, however, seem only to increase tax compliance of taxpayers who identify sufficiently with the group holding these norms. When identification is weak, social norms may have no effect and can even backfire. The present data, nonetheless, provide the reassuring finding that, at least in Australia, the large majority of taxpayers do identify strongly with their nation and their fellow citizens. Hence, for Australian tax authorities, strategies to increase tax compliance through reference to social norms and widely shared views about the importance to pay one's taxes honestly would seem promising (Wenzel, 2001b). Furthermore, tax authorities can indeed try to establish a sense of inclusive identification necessary for the normative power of widely held views and common behaviours. As Bardach (1989, p. 61, emphasis in the original) puts it, 'The problem of persuasion, then, is to induce the individual to change frames of reference and think of ... the citizenry in its entirety, the majority of whom are in fact compliant'. 


\section{REFERENCES}

Abrams, D., \& Hogg, M. A. (1990). Social identification, self-categorization and social influence. In W. Stroebe, \& M. Hewstone (Eds.), European review of social psychology (Vol. 1, pp. 195-228). Chichester, UK: Wiley.

Aiken, L. S., \& West, S. G. (1991). Multiple regression: Testing and interpreting interactions. Newbury Park, CA: Sage.

Ajzen, I. (1991). The theory of planned behavior. Organizational Behavior and Human Decision Processes, 50, 170-211.

Allingham, M., \& Sandmo, A. (1972). Income tax evasion: A theoretical analysis. Journal of Public Economics, 1, 323-338.

Alm, J., McClelland, G. H., \& Schulze, W. D. (1999). Changing the social norm of tax compliance by voting. Kyklos, 52, 141-171.

Bardach, E. (1989). Moral suasion and taxpayer compliance. Law and Policy, 11, 49-69.

Baron, R. M., \& Kenny, D. A. (1986). The moderator-mediator variable distinction in social psychological research: Conceptual, strategic, and statistical considerations. Journal of Personality and Social Psychology, 51, 1173-1182.

Bosco, L., \& Mittone, L. (1997). Tax evasion and moral constraints: Some experimental evidence. Kyklos, 50, 297-324.

Braithwaite, V. (2001). The community hopes, fears and actions survey: Goals and measures. Centre for Tax System Integrity Working Paper No. 2. Canberra: Australian National University. 
Brehm, S. S., \& Brehm, J. W. (1981). Psychological reactance: A theory of freedom and control. New York: Academic Press.

Brooks, N., \& Doob, A. N. (1990). Tax evasion: Searching for a theory of compliant behavior. In M. L. Friedland (Ed.), Securing compliance: Seven case studies. Toronto: University of Toronto Press.

Cialdini, R. B., Kallgren, C. A., \& Reno, R. R. (1991). A focus theory of normative conduct: A theoretical refinement and reevaluation of the role of norms in human behavior. In L. Berkowitz (Ed.), Advances in experimental social psychology (Vol. 24, pp. 201-234). San Diego, CA: Academic Press.

Cialdini, R. B., \& Trost, M. N. (1998). Social influence: Social norms, conformity, and compliance. In D. G. Gilbert, S. T. Fiske, \& G. Lindzey (Eds.), The handbook of social psychology (4 ed., Vol. 2, pp. 151-192). Boston, MA: McGraw-Hill.

De Juan, A., Lasheras, M. A., \& Mayo, R. (1994). Voluntary Tax Compliant Behavior of Spanish Income Tax Payers. Public Finance, 49, 90-105.

Deutsch, M., \& Gerard, H. B. (1955). A study of normative and informational social influences upon individual judgment. Journal of Abnormal and Social Psychology, 51, 629-636.

Elffers, H., Robben, H. S. J., \& Hessing, D. J. (1992). On measuring tax evasion. Journal of Economic Psychology, 13, 545-567.

Fishbein, M., \& Ajzen, I. (1975). Belief, attitude, intention, and behavior: An introduction to theory and research. Reading, MA: Addison-Wesley. 
Grasmick, H. G., \& Bursik Jr, R. J. (1990). Conscience, significant others, and rational choice: Extending the deterrence model. Law and Society Review, 24, 837-861.

Haslam, S. A. (2001). Psychology in organizations: The social identity approach. London: Sage.

Hasseldine, D. J., Kaplan, S. E., \& Fuller, L. R. (1994). Characteristics of New Zealand tax evaders: A note. Accounting and Finance, 34, 79-93.

Kelley, H. H. (1952). The two functions of reference groups. In G. E. Swanson, T. M. Newcomb, \& E. L. Hartley (Eds.), Readings in social psychology (pp. 410-414). New York: Holt.

Kelman, H. (1958). Compliance, identification, and internalization: Three processes of attitude change. Journal of Conflict Resolution, 2, 51 - 60.

Lewis, A. (1982). The psychology of taxation. Oxford: Martin Robertson.

McGarty, C., Turner, J. C., Oakes, P. J., \& Haslam, M. A. (1993). The creation of uncertainty in the influence process: The roles of stimulus information and disagreement with similar others. European Journal of Social Psychology, 23, 17-38.

McGraw, K. M., \& Scholz, J. T. (1991). Appeals to civic virtue versus attention to selfinterest: Effects on tax compliance. Law and Society Review, 25, 471-498.

Mearns, M., \& Braithwaite, V. (2001). The community hopes, fears and actions survey: Survey method, sample representativeness and data quality. Centre for Tax System Integrity Working Paper No. 4, Canberra: Australian National University. 
Porcano, T. M. (1988). Correlates of tax evasion. Journal of Economic Psychology, 9(1), 47-67.

Reckers, P. M. J., Sanders, D. L., \& Roark, S. J. (1994). The influence of ethical attitudes on taxpayer compliance. National Tax Journal, 47, 825-36.

Schmölders, G. (1970). Survey research in public finance: A behavioral approach to fiscal theory. Public Finance, 25, 300-306.

Schwartz, R., \& Orleans, S. (1967). On legal sanctions. University of Chicago Law Review, $34,274-300$.

Schwartz, S. H. (1977). Normative influences on altruism. In L. Berkowitz (Ed.), Advances in experimental social psychology (Vol. 10, pp. 221-279). New York: Academic Press.

Scott, W. J., \& Grasmick, H. (1981). Deterrence and income tax cheating: Testing interaction hypotheses in utilitarian theories. Journal of Applied Behavioral Science, 17, 395-408.

Sigala, M. (1999). Tax compliance and social influence. Unpublished doctoral thesis, University of Exeter, UK.

Sigala, M., Burgoyne, C., \& Webley, P. (1999). Tax communication and social Influence: Evidence from a British Sample. Journal of Community and Applied Social Psychology, 9, $237-241$

Simon, B. (1997). Self and group in modern society: Ten theses on the individual self and the collective self. In R. Spears, P. J. Oakes, N. Ellemers, \& S. A. Haslam (Eds.), The social psychology of stereotyping and group life (pp. 318-335). Oxford, UK: Blackwell. 
Spicer, M. W., \& Lundstedt, S. B. (1976). Understanding tax evasion. Public Finance, 31, 295-305.

Tajfel, H., \& Turner, J. C. (1986). The social identity theory of intergroup behavior. In S. Worchel, \& G. Austin (Eds.), Psychology of intergroup relations (pp. 7-24). Chicago: Nelson-Hall.

Terry, D. J., \& Hogg, M. A. (1996). Group norms and the attitude-behaviour relationship: A role for group identification. Personality and Social Psychology Bulletin, 22, 776-793.

Terry, D. J., Hogg, M. A., \& White, K. M. (2000). Attitude-behavior relations: Social identity and group membership. In D. J. Terry, \& M. A. Hogg (Eds.), Attitudes, behavior, and social context: The role of norms and group membership (pp. 67-93). Mahwah, NJ: Erlbaum.

Turner, J. C. (1987a). A self-categorization theory. In J. C. Turner, M. A. Hogg, P. J. Oakes, S. D. Reicher, \& M. S. Wetherell (Eds.), Rediscovering the social group: A selfcategorization theory (pp. 42-67). Oxford: Blackwell.

Turner, J. C. (1987b). The analysis of social influence. In J. C. Turner, M. A. Hogg, P. J. Oakes, S. D. Reicher, \& M. S. Wetherell (Eds.), Rediscovering the social group: A selfcategorization theory (pp. 68-88). Oxford: Blackwell.

Turner, J. C. (1991). Social influence. Buckingham, UK: Open University Press.

Turner, J. C., Hogg, M. A., Oakes, P. J., Reicher, S. D., \& Wetherell, M. S. (1987). Rediscovering the social group: A self-categorization theory. Oxford, UK: Basil Blackwell. 
Vogel, J. (1974). Taxation and public opinion in Sweden: An interpretation of recent survey data. National Tax Journal, 27, 499-513.

Wallschutzky, I. G. (1984). Possible causes of tax evasion. Journal of Economic Psychology, 5, 371-384.

Wallschutzky, I. G. (1996). Issues in research methods: With reference to income tax research. Unpublished manuscript. University of Newcastle, Australia.

Webley, P., Cole, M., \& Eidjar, O. P. (2001). The prediction of self-reported and hypothetical tax-evasion: Evidence from England, France and Norway. Journal of Economic Psychology, 22, 141-155.

Weigel, R. H., Hessing, D. J., \& Elffers, H. (1987). Tax evasion research: A critical appraisal and theoretical model. Journal of Economic Psychology, 8, 215-235.

Wenzel, M. (2001a). Misperceptions of social norms about tax compliance (1): A prestudy. Centre for Tax System Integrity Working Paper No. 7. Canberra: Australian National University.

Wenzel, M. (2001b). Misperceptions of social norms about tax compliance (2): A fieldexperiment. Centre for Tax System Integrity Working Paper No. 8. Canberra: Australian National University.

Wenzel, M. (2002). The impact of outcome orientation and justice concerns on tax compliance: The role of taxpayers' identity. Journal of Applied Psychology, 87, 629-645. 


\section{THE CENTRE FOR TAX SYSTEM INTEGRITY WORKING PAPERS}

No. 1. Braithwaite, V. \& Reinhart, M. The Taxpayers' Charter: Does the Australian Taxation Office comply and who benefits? December 2000.

No. 2. Braithwaite, V. The Community Hopes, Fears and Actions Survey: Goals and Measures. March 2001.

No. 3. Braithwaite, V., Reinhart, M., Mearns, M. \& Graham, R. Preliminary findings from the Community Hopes, Fears and Actions Survey. April 2001.

No. 4. Mearns, M., \& Braithwaite, V. The Community Hopes, Fears and Actions Survey: Survey method, sample representativeness and data quality. April 2001.

No. 5. Sakurai, Y. \& Braithwaite, V. Taxpayers' perceptions of the ideal tax adviser: Playing safe or saving dollars? May 2001.

No. 6. Wenzel, M. The impact of outcome orientation and justice concerns on tax compliance: The role of taxpayers' identity. June 2001.

No. 7. Wenzel, M. Misperceptions of social norms about tax compliance (1): A prestudy. June 2001.

No. 8. Wenzel, M. Misperceptions of social norms about tax compliance (2): A field-experiment. June 2001.

No. 9. Taylor, N. Taxpayers who complain about paying tax: What differentiates those who complain from those who don't? June 2001.

No. 10. Wenzel, M. Principles of procedural fairness in reminder letters and awareness of entitlements: A prestudy. June 2001.

No. 11. Taylor, N. \& Wenzel, M. The effects of different letter styles on reported rental income and rental deductions: An experimental approach. July 2001.

No. 12. Williams, R. Prosecuting non-lodgers: To persuade or punish? July 2001.

No. 13. Braithwaite, V. Tensions between the citizen taxpaying role and compliance practices. Forthcoming

No. 14. Taylor, N. Understanding taxpayer attitudes through understanding taxpayer identities. July 2001. 
No. 15. Shover, N., Job, J. \& Carroll, A. Organisational capacity for responsive regulation. August 2001.

No. 16. Tyler, T.R. Trust and law-abidingness: A proactive model of social regulation. August 2001.

No. 17. Genser, B. Corporate income taxation in the European Union: Current state and perspectives. August 2001.

No. 18. McBarnet, D. When compliance is not the solution but the problem: From changes in law to changes in attitude. August 2001.

No. 19. Schneider, F., Braithwaite, V. \& Reinhart, M. Individual behaviour in Australia's shadow economy: Facts, empirical findings and some mysteries. September 2001.

No. 20. Taylor, N. \& Wenzel, M. Comparing rental income and rental deductions for electronic versus paper lodgers: A follow-up investigation. November 2001.

No. 21. Braithwaite, J. Through the eyes of the advisers: A fresh look at tax compliance of high wealth individuals. September 2001.

No. 22. Pittelkow, Y., Braithwaite, J. \& Williams, R. Tax Compliance by the very wealthy: Red flags of risk. September 2001.

No. 23. Braithwaite, J. \& Williams, R. Meta risk management and tax system integrity. October 2001.

No. 24. Braithwaite, J \& Wirth, A. Towards a framework for large business tax compliance. November 2001.

No. 25. Murphy, K., Braithwaite, V. \& Sakurai, Y. Aggressive Tax Planning: Differentiating those playing the game from those who don't? October 2001.

No. 26. Morgan, S. \& Murphy, K. The 'Other Nation': Understanding rural taxpayers' attitudes toward the Australian tax system. December 2001

No. 27. Ahmed, E. \& Sakurai, Y. Small business individuals: What do we know and what do we need to know? December 2001.

No. 28. Hobson, K. Championing the compliance model: From common sense to common action. December 2001.

No. 29. Smart, M. The under thirty taxpayer: Different from the rest? Forthcoming.

No. 30. Job, J. \& Honaker, D. Short-term experience with responsive regulation in the Australian Taxation Office. May 2002. 
No. 31. Frey, B. A constitution for knaves crowds out civic virtues. June 2002.

No. 32. Feld, L. \& Frey, B. Trust breeds trust: How taxpayers are treated. June 2002.

No. 33. Wenzel, M. An analysis of norm processes in tax compliance. July 2002. 